\title{
Inhibition of various glutathione S-transferase isoenzymes by RRR-alpha-tocopherol
}

Citation for published version (APA):

van Haaften, R. I. M., Haenen, G. R. M. M., van Bladeren, P. J., Bogaards, J. J., Evelo, C. T. A., \& Bast, A. (2003). Inhibition of various glutathione S-transferase isoenzymes by RRR-alpha-tocopherol.

Toxicology in Vitro, 17(3), 245-251. https://doi.org/10.1016/S0887-2333(03)00038-9

Document status and date:

Published: 01/01/2003

DOI:

10.1016/S0887-2333(03)00038-9

Document Version:

Publisher's PDF, also known as Version of record

Document license:

Taverne

Please check the document version of this publication:

- A submitted manuscript is the version of the article upon submission and before peer-review. There can be important differences between the submitted version and the official published version of record.

People interested in the research are advised to contact the author for the final version of the publication, or visit the DOI to the publisher's website.

- The final author version and the galley proof are versions of the publication after peer review.

- The final published version features the final layout of the paper including the volume, issue and page numbers.

Link to publication

\footnotetext{
General rights rights.

- You may freely distribute the URL identifying the publication in the public portal. please follow below link for the End User Agreement:

www.umlib.nl/taverne-license

Take down policy

If you believe that this document breaches copyright please contact us at:

repository@maastrichtuniversity.nl

providing details and we will investigate your claim.
}

Copyright and moral rights for the publications made accessible in the public portal are retained by the authors and/or other copyright owners and it is a condition of accessing publications that users recognise and abide by the legal requirements associated with these

- Users may download and print one copy of any publication from the public portal for the purpose of private study or research.

- You may not further distribute the material or use it for any profit-making activity or commercial gain

If the publication is distributed under the terms of Article $25 \mathrm{fa}$ of the Dutch Copyright Act, indicated by the "Taverne" license above, 


\title{
Inhibition of various glutathione S-transferase isoenzymes by RRR- $\alpha$-tocopherol
}

\author{
Rachel I.M. van Haaften*, Guido R.M.M. Haenen, Peter J. van Bladeren ${ }^{1}$, \\ Jan J.P. Bogaards ${ }^{1}$, Chris T.A. Evelo ${ }^{2}$, Aalt Bast \\ Department of Pharmacology and Toxicology, Faculty of Medicine, Universiteit Maastricht, PO Box 616, 6200 MD Maastricht, The Netherlands
}

Accepted 1 March 2003

\begin{abstract}
The activity of human cytosolic glutathione S-transferases (GSTs) can positively or negatively be changed by various compounds. It is for instance known that RRR- $\alpha$-tocopherol inhibits GST P1-1 [Haaften van R.I.M. et al. (2001) Alpha-tocopherol inhibits human glutathione S-transferase pi. BBRC 280, 631-633]. The effect of RRR- $\alpha$-tocopherol on the other isoenzymes of GST in purified forms of the isoenzymes and in human liver cytosol (GST M and GST A) and lysate of human erythrocytes (GST P) is studied. It is found that all isoenzymes (purified enzymes and enzymes present in homogenates) are inhibited, in a concentrationdependent way, by RRR- $\alpha$-tocopherol. GST P is in both cases inhibited with the highest potency compared to the other isoenzymes. It also appeared that the purified GST P1-1 isoenzyme is non-competitively inhibited by RRR- $\alpha$-tocopherol. The IC 50 values of RRR- $\alpha$-tocopherol for the purified isoenzymes of GST are much lower compared to the $\mathrm{IC}_{50}$ values for human lysate and human liver cytosol. This is probably due to binding of RRR- $\alpha$-tocopherol to proteins, e.g. albumin and hemoglobin, with higher affinity than to GST; so more RRR- $\alpha$-tocopherol is needed to inhibit the enzyme. However, the inhibition of GSTs by RRR- $\alpha$ tocopherol can still be of physiological relevance, because due to dermal application of cosmetic products very high concentrations vitamin E can be reached in the skin, where GST P1-1 is present. RRR- $\alpha$-tocopherol might also be a good lead compound for the development of a new class of inhibitors of GST that can be used as adjuvant in cancer therapy.
\end{abstract}

(C) 2003 Elsevier Science Ltd. All rights reserved.

Keywords: Glutathione S-transferase; Isoenzyme; Vitamin E; Inhibition; Human

\section{Introduction}

The human body protects itself against harmful compounds by different mechanisms. An important line of defense is formed by the glutathione S-transferases (GSTs). These enzymes represent a major group of phase II metabolism enzymes, which catalyse the conjugation of glutathione with various electrophiles (Board et al., 1990, Mannervik, 1985). In most cases the electrophile becomes less toxic but in some cases the

\footnotetext{
* Corresponding author. Tel.: +31-43-3882914 or +31-433881417; fax: + 31433884149 .

E-mail address: rachel.vanhaaften@bigcat.unimaas.nl(R.I.M.van Haaften).

1 TNO Nutrition and Food Research, Toxicology Division, PO Box 360, 3700 AJ Zeist, The Netherlands.

2 BiGCaT bioinformatics group, Universiteit Maastricht and Technische Universiteit Eindhoven, P.O. Box 616, 6200 MD Maastricht, The Netherlands.
}

electrophile is activated. Multiple cytosolic and membrane-bound GST isoenzymes are known in humans, each of which displays distinct catalytic as well as binding properties. On the basis of their substrate specificity and kinetic characteristics the cytosolic isoenzymes can be classified into four major classes, A (alpha), M (mu), $\mathrm{P}$ (pi) and T (theta). All cytosolic isoenzymes are dimers of two subunits. Within the mu and alpha classes several distinct GST subunits, denoted with Arabic numerals, have been characterised and a high degree of heterogeneity has been documented among the GSTs of these two classes in human tissues (Awasthi et al., 1994, Mannervik, 1985). The cytosolic isoforms are differentially expressed in the different organs in the human body. It is also possible that one organ expresses more than one isoform of GST. The human liver for example expresses the alpa and the mu form of GST and the mu isoform of the enzyme is expressed in for example the adrenal gland, the kidney, the testis and the liver. 
Human erythrocytes only express the pi isoform of the enzyme (Awasthi et al., 1994, Board et al., 1990). The pi class isoenzyme appears the most widely distributed GST isoenzyme and is the most abundant form found in many tissues (Awasthi et al., 1994, Board et al., 1990), and is the GST isoenzyme mostly expressed in tumour cells (Ouwerkerk, Mahadevan and Mulder, 1998). GST M1 is expressed in only $60 \%$ of human individuals. It has been reported that people lacking the GST M1 have a higher risk of developing lung cancer (Bladeren van and Ommen van 1991, Board et al., 1990).

The activity of the human glutathione S-transferase enzymes can be influenced by multiple compounds. In previous studies we have found that different forms of vitamin $\mathrm{E}$ (tocopherols, tocotrienols and different esters of tocopherol) can inhibit the activity (GSH conjugation) of purified GST P1-1 (Haaften van et al., 2001a, Haaften van et al., 2001b).

In the present study, the effect of RRR- $\alpha$-tocopherol (the form of vitamin $\mathrm{E}$ most abundantly present in humans and the vitamer with the highest potency in inhibiting GST P1-1) on the activity of various purified GST isoenzymes is compared. Also the effect of RRR$\alpha$-tocopherol on GST activity in lysate of human red blood cells and cytosol of human liver is studied. As stated above, in red blood cells only the pi isoform of GST is present and in human liver both the mu and the alpha isoform of GST are the most prominent forms.

\section{Materials and methods}

\subsection{Chemicals}

RRR - $\alpha$ - tocopherol, 1 - chloro - 2,4 - dinitrobenzene (CDNB), hemoglobin and albumin were obtained from Sigma (St. Louis, USA). Reduced glutathione (GSH) was obtained from ICN Biomedicals Inc. (Costa Mesa, USA). Purified human glutathione S-transferases (GST A1-1 (98\%), GST A2-2 (94\%), GST M1a-1a (100\%) and GST P1-1(98\%)) were a gift of TNO Nutrition and Food Research (Zeist, The Netherlands). The specific activities with CDNB of these isoenzymes are respectively $123 \mathrm{U} / \mathrm{mg}, 64 \mathrm{U} / \mathrm{mg}, 262 \mathrm{U} / \mathrm{mg}$ and $53 \mathrm{U} / \mathrm{mg}$. All other chemicals were of analytical grade purity.

\subsection{Human lysate}

Human blood, from a healthy female volunteer (25 years), was collected in an EDTA-tube. After centrifugation at $3000 \mathrm{rpm}\left(10 \mathrm{~min}\right.$ at $\left.4{ }^{\circ} \mathrm{C}\right)$ the plasma was removed from the erythrocytes. The erythrocytes were washed three times with an equal volume cold phosphate buffered salt (PBS). These washed erythrocytes are lysed with ice cold milliQ water. After 10 min on ice, the solution is mixed vigorously and centrifuged at 5000 rpm (10 min at $4{ }^{\circ} \mathrm{C}$ ) (supernatant is lysate). Before measuring the glutathione S-transferase activity the human lysate was diluted 60 times with $100 \mathrm{mM}$ potassium phosphate, $\mathrm{pH} 6.5$.

\subsection{Human liver cytosol}

Cytosol was prepared from a small piece of human liver (purchased from a male patient) with hepatoma. The part next to the removed tumour has been used in this experiment. After removal, the piece of liver was homogenised $(1: 2, \mathrm{w} / \mathrm{v})$ in ice cold potassium phosphate buffer ( $50 \mathrm{mM}$, pH 7.4) containing $0.1 \mathrm{mM}$ EDTA. The homogenate was centrifuged at $10000 \times g(20 \mathrm{~min}$ at $4{ }^{\circ} \mathrm{C}$ ). Subsequently the supernatant was centrifuged at $10000 \times g\left(20 \mathrm{~min}\right.$ at $\left.4{ }^{\circ} \mathrm{C}\right)$ and again at $65000 \times g(60$ min at $\left.4{ }^{\circ} \mathrm{C}\right)$. The supernatant was collected and stored at $-80{ }^{\circ} \mathrm{C}$. Before use the cytosol was thawed and diluted 6000 times with $100 \mathrm{mM}$ potassium phosphate, $\mathrm{pH} 6.5$.

\subsection{Assay of glutathione S-transferase activity}

GST activity was measured as described by Mannervik and Guthenberg (1981) with slight modifications. In short, the reaction of $1 \mathrm{mM}$ CDNB with $1 \mathrm{mM} \mathrm{GSH}$ in purified enzyme (in $100 \mathrm{mM}$ potassium phosphate, $\mathrm{pH}$ 6.5) or in the diluted human liver cytosol or lysate of erythrocytes was monitored spectrophotometrically by recording the increase in absorbance at $340 \mathrm{~nm}$ at $37^{\circ} \mathrm{C}$. Effects of various concentrations of RRR- $\alpha$-tocopherol on GST activity were determined. A stock solution of $\alpha$ tocopherol was prepared in ethanol. The final concentration of ethanol in the incubation mixture was $1 \% \mathrm{v} /$ $\mathrm{v}$; this concentration of ethanol had no effect on GST activity. The mixture of the purified GST enzyme $(0.4$ $\mu \mathrm{g}$ protein $/ \mathrm{ml}$ buffer) or the human liver cytosol or lysate of erythrocytes with RRR- $\alpha$-tocopherol was incubated for $2 \mathrm{~min}$ at $37{ }^{\circ} \mathrm{C}$ before activity measurement. A correction for the spontaneous reaction between GSH and CDNB in the absence of enzyme and in the presence of ethanol $(1 \%)$ was made. Ethanol was added because $\alpha$-tocopherol was dissolved in ethanol. The $\mathrm{IC}_{50}$ of the purified enzyme is normalised on enzyme activity.

To study the inhibitory mechanism of RRR- $\alpha$-tocopherol on the glutathione S-transferase P1-1 activity (of the purified enzyme), substrate concentrations (CDNB or GSH) were varied. When CDNB was varied the GSH concentration was kept at $1 \mathrm{mM}$ and vice versa. In these experiments the concentration RRR- $\alpha$-tocopherol was kept constant at $0.6 \mu \mathrm{M}$.

The effect of the combined addition of RRR- $\alpha$-tocopherol with two proteins, hemoglobin and albumin, on the activity of purified human glutathione S-transferase P1-1 enzyme was also studied. Effects of a fixed concentration RRR- $\alpha$-tocopherol with a fixed concen- 
tration of hemoglobin or albumin were determined. The mixture of purified human glutathione S-transferase P11 enzyme $(0.0095 \mathrm{U} / \mathrm{ml}$ in $100 \mathrm{mM}$ potassium phosphate buffer $\mathrm{pH}$ 6.5) with RRR- $\alpha$-tocopherol and albumin or hemoglobin was incubated for $2 \mathrm{~min}$ at $37^{\circ} \mathrm{C}$ before activity measurement. A correction for the spontaneous reactions between GSH and CDNB in the absence of enzyme and in the presence of ethanol, RRR- $\alpha$-tocopherol, hemoglobin or albumin was made.

\section{Results}

\subsection{Purified isoenzymes}

All purified isoenzymes tested are inhibited by RRR$\alpha$-tocopherol in a concentration dependent manner. The concentrations RRR- $\alpha$-tocopherol giving $50 \%$ inhibition $\left(\mathrm{IC}_{50}\right)$ of GST activity are depicted in Fig. 1. The $\mathrm{IC}_{50}$ of RRR- $\alpha$-tocopherol varies for the different isoenzymes of GST investigated. The $\mathrm{IC}_{50}$ of RRR- $\alpha-$ tocopherol on GST P1-1 is the lowest compared to the other isoenzymes tested $\left(\mathrm{IC}_{50}\right.$ is $\left.0.6 \pm 0.06 \mu \mathrm{M}\right)$. The concentration of RRR- $\alpha$-tocopherol needed to inhibit the activity of GST A1-1 ( $\mathrm{IC}_{50}$ is $\left.0.9 \pm 0.08 \mu \mathrm{M}\right)$ and GST M1a-1a ( $\mathrm{IC}_{50}$ is $\left.1.2 \pm 0.06 \mu \mathrm{M}\right)$ is higher compared to that of GST P1-1. The catalytic activity of GST A2-2 $\left(\mathrm{IC}_{50} 3.5 \pm 0.06 \mu \mathrm{M}\right)$ is inhibited by $\mathrm{RRR}$ - $\alpha$-tocopherol with a much lower potency compared to the other isoenzymes tested.

For the GST P1-1 isoenzyme the nature of the inhibition by RRR- $\alpha$-tocopherol was studied. GST activity was measured with variable concentrations of either GSH (Fig. 2) or CDNB (data not shown) in the presence of a fixed concentration of RRR- $\alpha$-tocopherol. From Fig. 2 it appears that RRR- $\alpha$-tocopherol lowers the $\mathrm{V}_{\max }$ values (from $18 \mu \mathrm{mol} / \mathrm{min} \cdot \mathrm{mg}$ to $5 \mu \mathrm{mol} /$ min $\cdot \mathrm{mg}$ (enzyme concentration is $0.0002 \mathrm{U} / \mathrm{ml}$ )), but does not affect the $K_{\mathrm{m}}(0.9 \mathrm{mM})$. A similar type of inhibition is obtained with $\mathrm{CDNB}$ as substrate. In the Eadie-Hofstee plot (insert in Fig. 2) two parallel lines are observed with and without the addition of $0.6 \mu \mathrm{M}$ RRR- $\alpha$-tocopherol. This confirms that RRR- $\alpha$-tocopherol exhibits a non-competitive inhibition on GST P1-1 with respect to the substrates GSH and CDNB.

\subsection{Human liver cytosol and lysate of erythrocytes}

As shown in Fig. 3 RRR- $\alpha$-tocopherol also inhibits the glutathione S-transferase activity in human liver cytosol and in lysate of human erythrocytes in a concentration dependent manner. The $\mathrm{IC}_{50}$ of GST activity in erythrocyte lysate is $103 \pm 17 \mu \mathrm{M}$ and in human liver cytosol $281 \pm 4 \mu \mathrm{M}$.

In Fig. 4, the effect of the addition of hemoglobin or albumin to an incubation of RRR- $\alpha$-tocopherol with

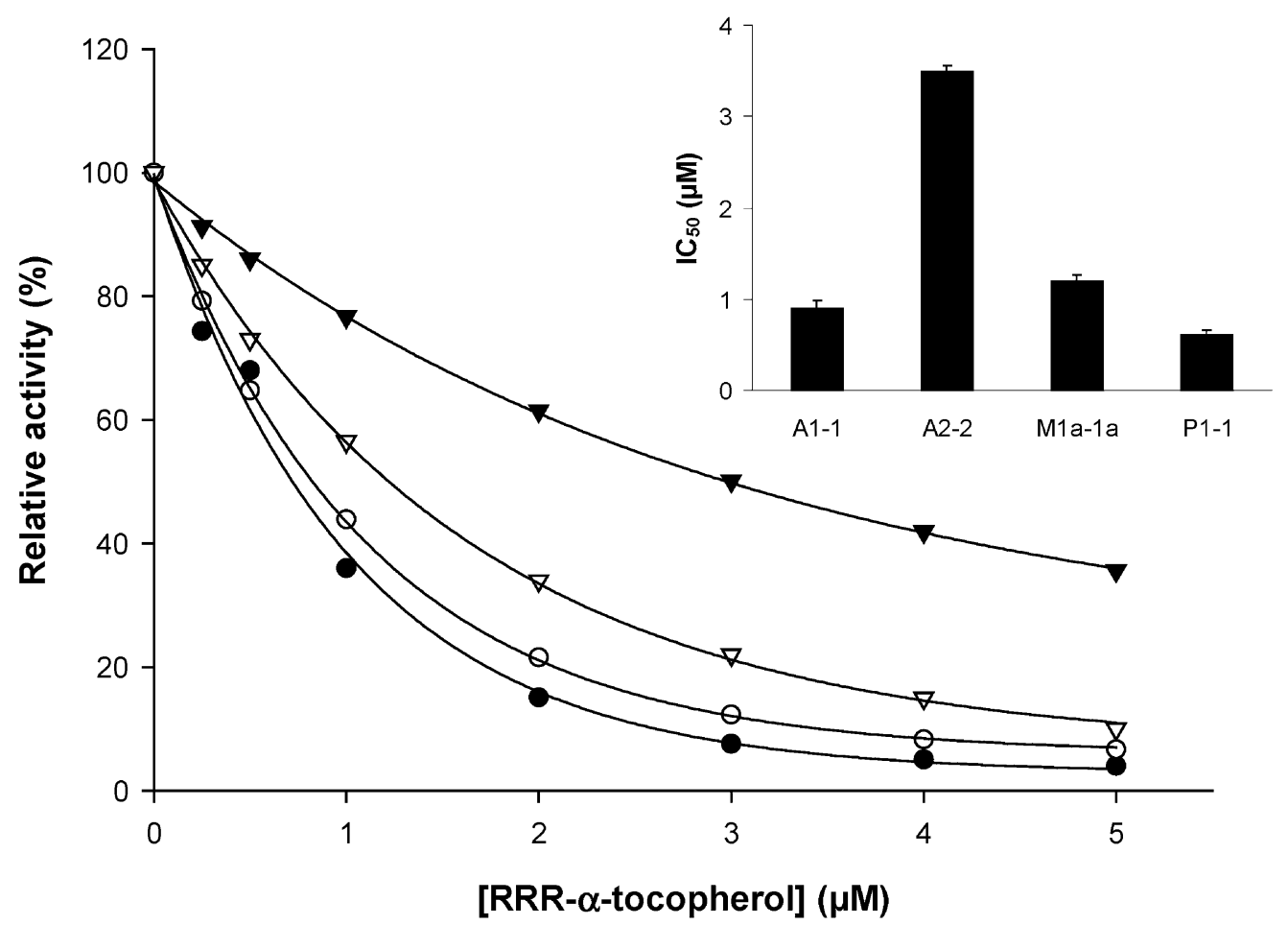

Fig. 1. Effect of RRR- $\alpha$-tocopherol on the activity of different purified glutathione S-transferase isoforms. The GST activity was measured by following the reaction between $1 \mathrm{mM}$ glutathione and $1 \mathrm{mM}$ 1-chloro-2,4-dinitrobenzene at $37^{\circ} \mathrm{C}$. Insert: $\mathrm{IC}_{50}$ values indicate means $( \pm \mathrm{SEM})$ of three independent experiments each performed in duplicate. 


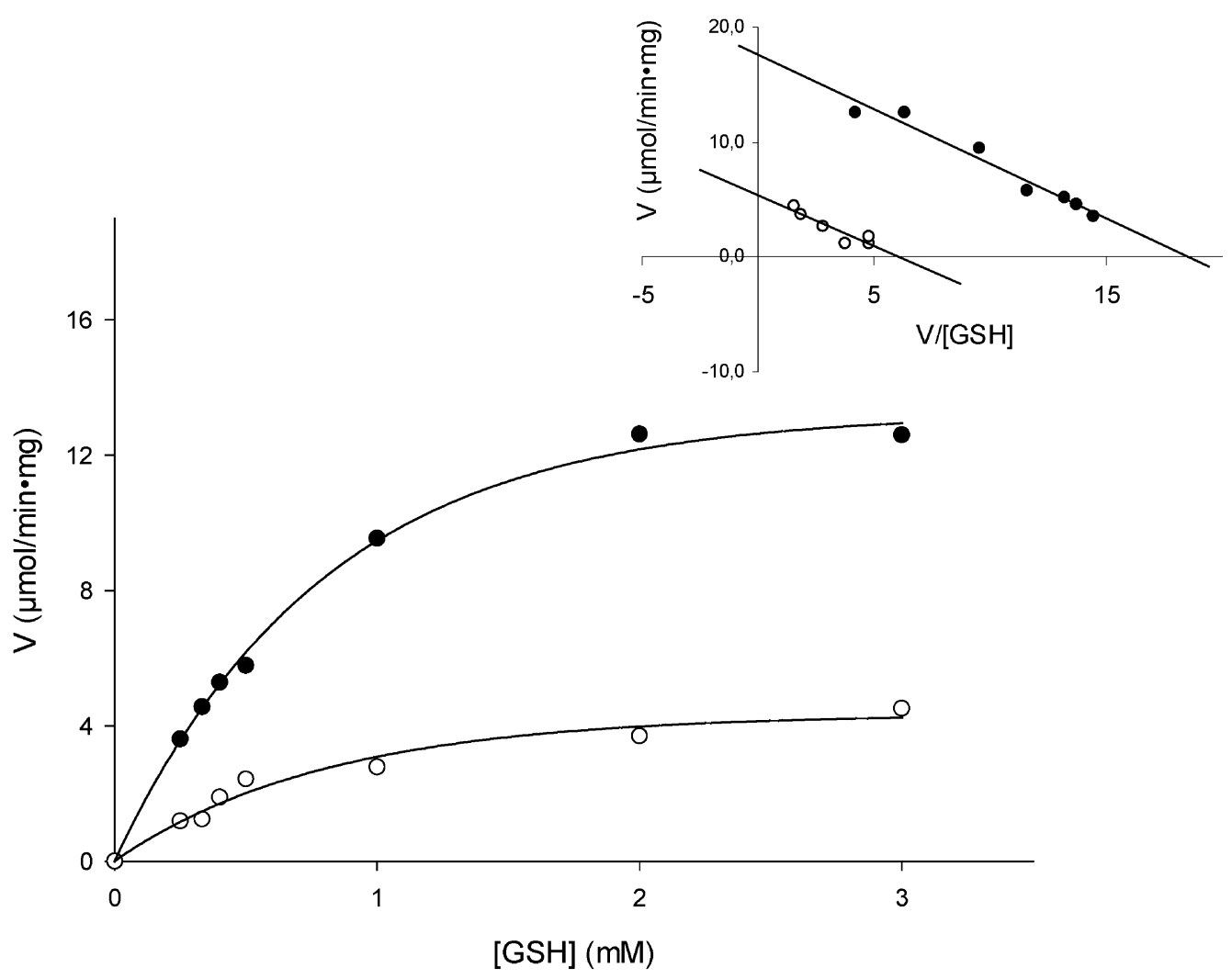

Fig. 2. Effect of RRR- $\alpha$-tocopherol on the activity of GST P1-1. The $K_{\mathrm{m}}$ and $\mathrm{V}_{\max }$ for GSH in the incubation without RRR- $\alpha$-tocopherol ( $)$ are respectively $0.9 \mathrm{mM}$ and $18 \mu \mathrm{mol} / \mathrm{min} \cdot \mathrm{mg}$. In the presence of $0.6 \mu \mathrm{M} \mathrm{RRR}-\alpha$-tocopherol $(\bigcirc)$ these values are $0.9 \mathrm{mM}$ and $5 \mu \mathrm{mol} / \mathrm{min} \cdot \mathrm{mg}$. Insert: Eadie-Hofstee plot showing non-competitive inhibition of human GST P1-1 isoenzyme towards GSH by RRR- $\alpha$-tocopherol. The experiments are performed at an enzyme concentration of $0.002 \mathrm{U} / \mathrm{ml}$. The data points are the mean of two independent experiments performed in triplicate.

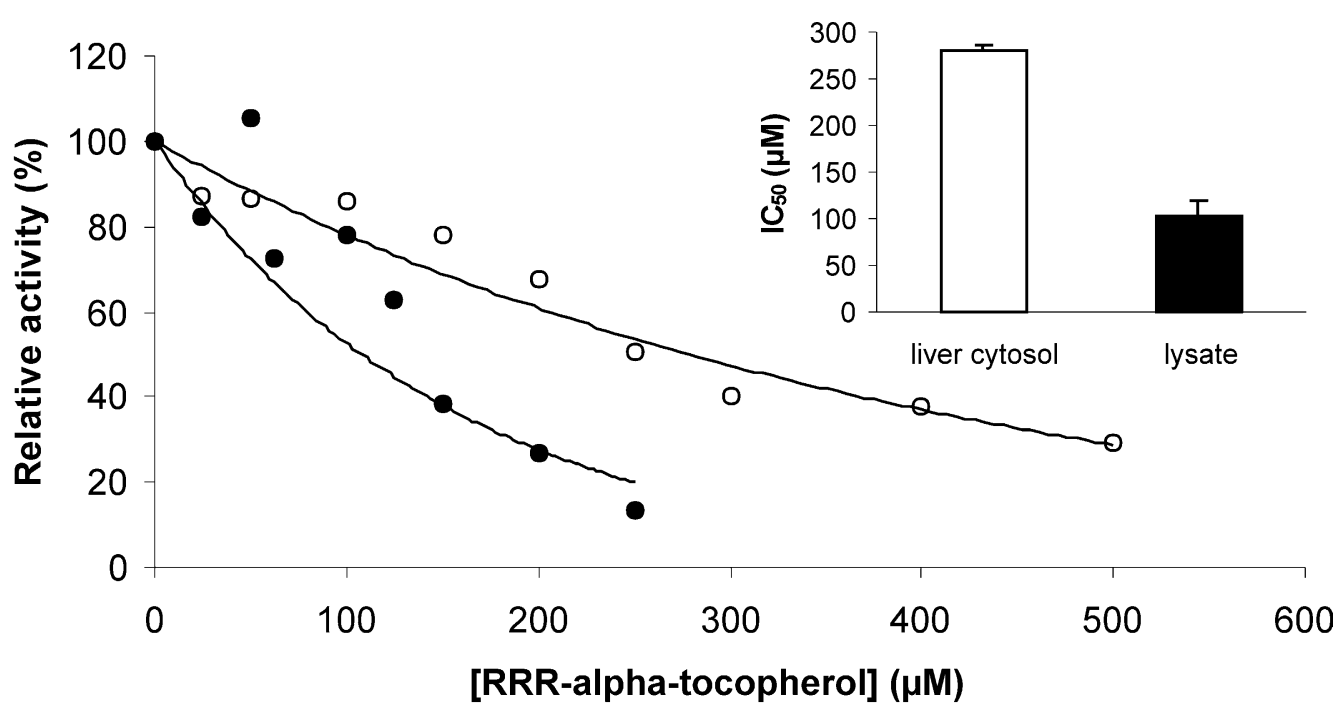

Fig. 3. Effect of RRR- $\alpha$-tocopherol on the activity of glutathione S-transferase in human lysate ( ) and in human liver cytosol (O). The GST activity was measured by following the reaction between $1 \mathrm{mM}$ glutathione and $1 \mathrm{mM}$ 1-chloro-2,4-dinitrobenzene at $37{ }^{\circ} \mathrm{C}$. The $\mathrm{IC}_{50}$ values for $\mathrm{RRR}-\alpha$-tocopherol (insert) are $103( \pm 17) \mu \mathrm{M}$ in the human lysate and $281( \pm 4) \mu \mathrm{M}$ in the human liver cytosol. $\mathrm{IC}_{50}$ values indicate means $( \pm \mathrm{SEM})$ of three independent experiments each performed in duplicate. 


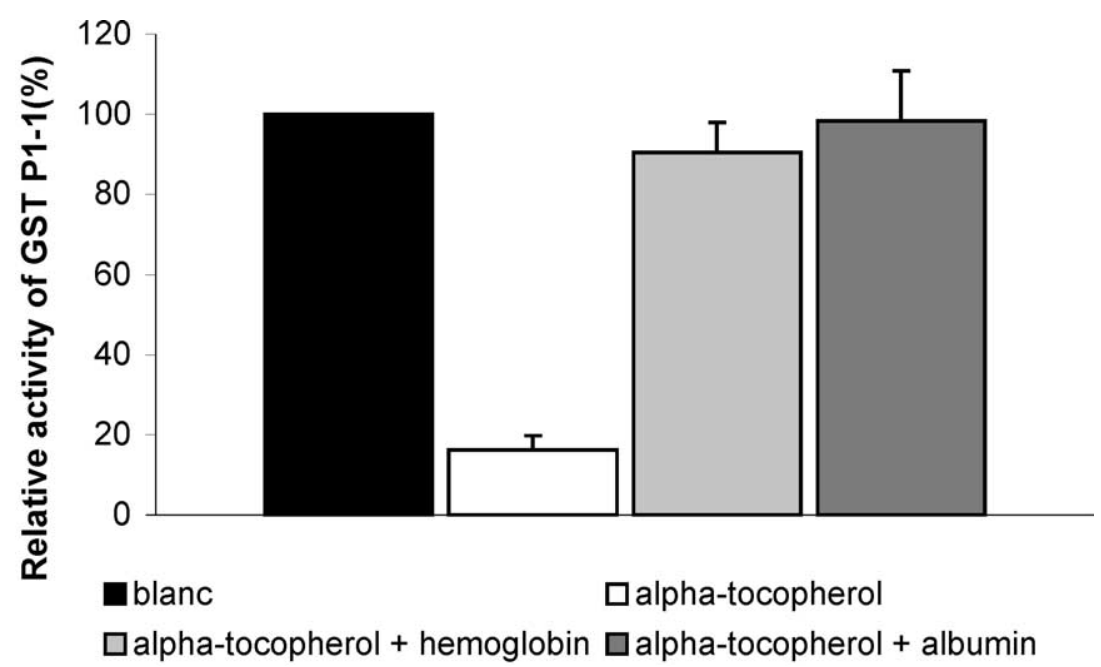

Fig. 4. Effect of the addition of hemoglobin or albumin to an incubation of RRR- $\alpha$-tocopherol with purified GST P1-1. In the blank incubation the GST P1-1 activity is set at $100 \%$. Addition of $2 \mu \mathrm{M}$ RRR- $\alpha$-tocopherol diminished the GST activity to $16 \pm 3 \%$. After addition of hemoglobin or albumin the GST activity is only diminished to $90 \pm 7 \%$ and $98 \pm 12 \%$, respectively. The values indicate means $( \pm$ SEM) of three independent experiments each performed in duplicate.

purified GST P1-1 is depicted. When the purified GST P1-1 enzyme is incubated wit $2 \mu \mathrm{M}$ RRR- $\alpha$-tocopherol the activity of the GST P1-1 is diminished to $16 \%$. When albumin or hemoglobin is included in the incubation with purified enzyme, $2 \mu \mathrm{M}$ RRR- $\alpha$-tocopherol far less diminished (to $98 \%$ and $90 \%$, respectively) the GST activity.

\section{Discussion}

GST isoenzymes are differentially expressed in different tissues. The pi isoform is for example expressed in red blood cells, placenta and skin. The alpha and mu isoforms are expressed in the liver. In the present study the effect of RRR- $\alpha$-tocopherol on different purified GST isoenzymes is studied. To test the effect of RRR- $\alpha-$ tocopherol on different GST isoenzymes in human homogenates we used human red blood cell lysate and cytosol of human liver.

It is found that purified human GST A1-1, A2-2, M1a-1a and P1-1 are inhibited, in a concentration dependent way, by RRR- $\alpha$-tocopherol. The concentration of RRR- $\alpha$-tocopherol needed to inhibit the isoenzyme with $50 \%$ is not the same for the different isoenzymes. The $\mathrm{IC}_{50}$ of RRR- $\alpha$-tocopherol on GST P11 is the lowest compared to the other isoenzymes tested. The $\mathrm{IC}_{50}$ of GST A1-1 and GST M1a-1a are higher compared to GST P1-1 and the $\mathrm{IC}_{50}$ of GST A2-2 is the highest of all isoenzymes tested. The $\mathrm{IC}_{50}$ of RRR- $\alpha$ tocopherol on GST A1-1 is approximately 4 times lower than on GST A2-2. Compared to previous described inhibitors of GST, RRR- $\alpha$-tocopherol has a high potency (Haaften van et al., 2001a; Mannervik and Danielson 1988). For the most sensitive GST isoenzyme
(GST P1-1) the nature of the inhibition by RRR- $\alpha$ tocopherol was found to be non-competitive.

From this study it also appeared that RRR- $\alpha$-tocopherol can inhibit glutathione S-transferase activity in human homogenates containing different isoforms of the enzyme. The inhibition by RRR- $\alpha$-tocopherol is concentration dependent. GST P1-1, present in lysate of human erythrocytes, is inhibited with an $\mathrm{IC}_{50}$ value of $103 \mu \mathrm{M}$ and the GST present in human liver cytosol (a combination of mu and alpha) is inhibited with an $\mathrm{IC}_{50}$ value of $281 \mu \mathrm{M}$. The $\mathrm{IC}_{50}$ of $\mathrm{RRR}-\alpha$-tocopherol is lower for the GST present in human erythrocytes (pi isoform) than for the GST present in human liver cytosol (a combination of mu and alpha isoforms). These results are in accordance with the results of the experiments with the purified isoenzymes of GST, which show that the GST P isoform is inhibited with a lower $\mathrm{IC}_{50}$ compared to the mu and alpha isoforms of human GST.

The $\mathrm{IC}_{50}$ values of the experiment with the purified isoenzymes of GST are much lower compared to the $\mathrm{IC}_{50}$ values of the experiment with human lysate and human liver cytosol. This difference can probably be explained by binding of RRR- $\alpha$-tocopherol to proteins, e.g. albumin and hemoglobin, with higher affinity than to GST; more RRR- $\alpha$-tocopherol is needed to inhibit the enzyme.

The inhibition of glutathione S-transferase can have opposite effects. On the one hand the inhibition of the enzyme can have toxic consequences, because the detoxification activity of the enzyme is decreased. Electrophilic compounds are not well detoxified and can do harm to DNA, proteins and lipids which can result in multiple diseases including cancer and neurodegenerative disorders. Inhibition of GST can in principle have the same consequence as GST deficiency because in 
both cases the catalytic activity of the enzyme is not executed. From literature it is known that approximately $40 \%$ of the human population is deficient for the GST M1 (Bladeren van and Ommen van 1991; Board et al., 1990). Experimental studies have reported that people lacking the GST M1 null phenotype have a higher risk of developing lung, bladder and larynx cancer (Lafuente et al., 1993; Poppel van et al., 1992). Therefore inhibition of GST M1 by RRR- $\alpha$-tocopherol is expected to increase the risk of developing various types of neoplastic disease. Genetically determined deficiency of the alpha and pi classes GSTs appears to be extremely rare (Board et al., 1990), suggesting a pivotal role of these isoenzymes.

On the other hand it can be positive to inhibit the detoxification activity of the GST enzyme. Overexpression of certain GST isoenzymes in tumour cells contributes to resistance against cytostatic drugs through GSH conjugation of the active metabolites (Burg et al., 2002; Morgan et al., 1996; Mulder and Ouwerkerk Mahadevan, 1997). Therefore, compounds are being developed that inhibit GST activity and can be used as adjuvant in cancer therapy (Burg et al., 2002). In this respect GST P1-1 is of interest since this is the class of GST overexpressed in various tumours (Ouwerkerk Mahadevan and Mulder, 1998). The inhibitors of GST that have been discovered thus far have little effect on GST P1-1 (Ouwerkerk Mahadevan and Mulder, 1998). As shown in this study RRR- $\alpha$-tocopherol has the highest potency for inhibition of GST P1-1. The inhibitors of GST that have been reported are ethacrynic acid and GSH-derived structures (Mulder and Ouwerkerk Mahadevan, 1997). These inhibitors are highly lipophilic. A potent inhibitor of cytosolic GST in vivo has to enter the cell, so it has to be lipophilic or utilise a carrier system for uptake. Because the GSH-conjugates are very hydrophilic and highly charged they cannot pass the lipophilic membrane of the cells and enter the cell (Burg et al., 2002). $\mathrm{RRR}-\alpha$-tocopherol is very lipophilic and can pass the cell membrane.

The previously reported inhibitors of GST activity exert their action by binding to the hydrophobic pocket of the active site of GST (H-site) (Burg et al., 2002). We have reported previously that RRR- $\alpha$ - tocopherol probably binds to a lipophilic pit-like structure in GST P1-1. Binding of RRR- $\alpha$-tocopherol to this site induces a conformational change of the GST molecule and in this way the activity of the enzyme is diminished (Haaften van et al., 2002). RRR- $\alpha$-tocopherol uses a new mechanism for GST inhibition and possibly RRR$\alpha$-tocopherol can be used as lead compound for developing of good GST P1-1 inhibitors in vivo.

Although the isoenzymes of GST in human homogenates are inhibited by RRR- $\alpha$-tocopherol with less potency compared to purified isoenzymes (probably due to the presence of other proteins), the inhibition of GSTs by RRR- $\alpha$-tocopherol can still be of physiological relevance. A lot of products contain relatively high concentrations vitamin E. In cosmetic products, which are applied to the skin in which GST P1-1 is present, up to $5 \%$ vitamin $\mathrm{E}$ can be found. Even products containing pure vitamin E are sold. Dermal application of these cosmetic products will increase of vitamin E levels in the skin (Fiume, 2002). These levels can be high enough to inhibit GST activity.

\section{References}

Awasthi, Y.C., Sharma, R., Singhal, S.S., 1994. Human glutathione S-transferases. The International Journal of Biochemistry 26, 295-308.

Bladeren van, P.J., Ommen van, B., 1991. The inhibition of glutathione S-transferases: mechanisms, toxic consequences and therapeutic benefits. Pharmacology and Therapeutics 51, 35-46.

Board, P., Coggan, M., Johnston, P., Ross, V., Suzuki, T., Webb, G., 1990. Genetic heterogeneity of the human glutathione transferases: a complex of gene families. Pharmacology and Therapeutics 48, 357-369.

Burg, D., Hameetman, L., Filippov, D.V., van der Marel, G.A., Mulder, G.J., 2002. Inhibition of glutathione S-transferase in rat hepatocytes by a glycine-tetrazole modified S-alkyl-GSH analogue. Bioorganic and Medicinal Chemistry Letters 12, 1579-1582.

Fiume, I.Z., 2002. Final report on the safety assessment of tocopherol, tocopheryl acetate, tocopheryl linoleate, tocopheryl linoleate/ oleate, tocopheryl nicotinate, tocopheryl succinate, dioleyl tocopheryl methylsilanol, potassium ascorbyl tocopheryl phosphate, and tocophersolan. International Journal of Toxicology 21, 51-116.

Haaften van, R.I.M., Evelo, C.T.A., Haenen, G.R.M.M., Bast, A., 2001a. Alpha-tocopherol inhibits human glutathione S-transferase pi. Biochemical and Biophysical Research Communications 280, 631-633.

Haaften van, R.I.M., Evelo, C.T.A., Penders, J., Eijnwachter, M.P.F., Haenen, G.R.M.M., Bast, A., 2001b. Inhibition of human glutathione S-transferase P1-1 by tocopherols and alpha-tocopherol derivatives. Biochimica et Biophysica Acta 1548, 23-28.

Haaften van, R.I.M., Haenen, G.R.M.M., Evelo, C.T.A., Bast, A., 2002. Tocotrienols inhibit human glutathione S-transferase P1-1. International Union of Biochemistry and Molecular Biology Life $54,81-84$.

Lafuente, A., Pujol, F., Carretero, P., Villa, J.P., Cuchi, A., 1993. Human glutathione S-transferase mu (GST mu) deficiency as a marker for the susceptibility to bladder and larynx cancer among smokers. Cancer Letters 68, 49-54.

Mannervik, B., 1985. The isoenzymes of glutathione transferase. Advances in enzymology and related areas of molecular biology 57, 357-417.

Mannervik, B., Danielson, U.H., 1988. Glutathione transferasesStructure and catalytic activity. Critical Reviews in Biochemistry and Molecular Biology 23, 283-337.

Mannervik, B., Guthenberg, C., 1981. Glutathione transferase (Human placenta). Methods in Enzymology 77, 231-235.

Morgan, A.S., Ciaccio, P.J., Tew, K.D., Kauvar, L.M., 1996. Isozyme-specific glutathione S-transferase inhibitors potentiate drug sensitivity in cultured human tumor cell lines. Cancer Chemotherapy and Pharmacology 37, 363-370.

Mulder, G.J., Ouwerkerk Mahadevan, S., 1997. Modulation of glu- 
tathione conjugation in vivo: how to decrease glutathione conjugation in vivo or in intact cellular systems in vitro. Chemico-Biological Interactions 105, 17-34.

Ouwerkerk Mahadevan, S., Mulder, G.J., 1998. Inhibition of glutathione conjugation in the rat in vivo by analogues of glutathione conjugates. Chemico-Biological Interactions 111-112, 163-176.

Poppel van, G., Vogel de, N., Bladeren van, P.J., Kok, F.J., 1992. Increased cytogenetic damage in smokers deficient in glutathione S-transferase isozyme mu. Carcinogenesis 13, 303-305. 